\title{
NOTAS SOBRE TUNGIDAE, I. NOVOS DADOS SOBRE A BIOLOGIA E MORFOLOGIA DE TUNGA PENETRANS (L., 1758) JAROCKI, 1838 (SIPHONAPTERA-TUNGIDAE)
}

\author{
Roséli Azi Nascimento ${ }^{1}$ \\ Tania Heloisa de Araujo Arigony ${ }^{2}$
}

\section{INTRODUÇÃO}

As pulgas do gênero TUNGA são penetrantes e necessitam de um aporte sangüineo permanente para o desenvolvimento de seus ovos. Tunga penetrans (L. 1758) Jarocki, 1838 , tem se revelado ultimamente agravo à saúde pública das populações marginais das grandes cidades constituindo-se, este fato, na urbanização de um problema anteriormente rural.

Sendo uma parasitose em várias áreas urbanas, periféricas e de populações de baixo poder aquisitivo, a Tungíase somente agora vem recebendo atenção das autoridades públicas, o que possibilitou o início de atividades de pesquisa biológica nesta área.

Medidas profiláticas e de controle deste parasito só poderão ser eficientes através do conhecimento detalhado do ciclo evolutivo e das condições ambientais favoráveis ao seu desenvolvimento.

Tais tarefas foram pouco trabalhadas pelos diferentes autores. BONNET (1887), FAUST \& MAXWELL (1930), BRUCE (1942), DEL PONTE (1950), SEGUY (1951), JAMES (1969) e REY (1973), desenvolveram estudos sobre o ovo e a larva, registrando dados discordantes sobre os diferentes estágios. Da mesma forma, VAZ \& URIEL (1946) e JOHNSON (1957) trabalharam as formas adultas chegando, também,'a diferentes ponderações.

O presente trabalho constitui-se, pois, em um primeiro passo para este conhecimento tratando-se do confronto entre as considerações contidas na literatura e o que foi possível levantar a respeito das diferentes etapas do desenvolvimento e da sua morfologia com o auxílio da microscopia eletrônica de varredura.

\section{ABSTRACT}

New data on the biology and morphology of Tunga penetrans (L., 1758) Jarocki, 1838 (Siphonaptera-Tungidae) are presented. In this paper is given a comparision between those points found at the literature with the new ones which have been pointed out, such as different aspects of the larval structural, a particular description of the eggbreaker, and morphological details of adults obtained by using scanning electron microscope. New data about evolution period are given.

1. Bolsista CNPq-proc. 825198-88.7.

2. Bolsista CNPq-proc. 305366/76.ZO.7. Trabalho realizado parcialmente com o apoio da FINEP proc. 4.2.87.0740.00. Pesquisadores do Centro de Identificação da Fauna Urbana - Museu de Ciências Naturais da Fundação Zoobotânica do RS - Rua Salvador França 1427 - CEP 90610 $\mathrm{POA} / \mathrm{RS}$. 


\section{MATERIAL E MÉTODOS}

O material estudado é procedente da Ilha das Flores, Porto Alegre, RS, situado no estuário do Rio Gua1ba à $29^{\circ} 59^{\prime} 14^{\prime \prime} \mathrm{S}$ e $51^{\circ} 14^{\prime} 36^{\prime \prime}$, resultante de 3 coletas, em dias ao acaso, dos pés de um único hospedeiro que apresentava 120 parasitas dos quais se obtiveram 4.569 ovos. Estes foram distribuidos, aleatoriamente, em 8 placas de Petri com areia da localidade da coleta e 3 placas com dieta preparada em laboratório. Estas placas foram colocadas em câmara climática tipo BOD, à temperatura de $26^{\circ} \mathrm{C}$ e umidade relativa variando entre $85-95 \%$.

As larvas obtidas destes ovos foram transferidas para placas com 2 tipos de substratos:

SUBSTRATO A: areia do local, sangue humano seco raspado, fezes de pulgas adultas;

SUBSTRATO B: dieta publicada por SINGH \& PRITAN (1976).

- extrato de carne. . . . . . . . . . . . . . . . . l g

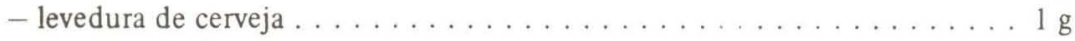

- casaminoácidos ...................... $1 \mathrm{~g}$

- hemoglobina . . . . . . . . . . . . . . . . . $100 \mathrm{~g}$

- sangue fresco coagulado. . . . . . . . . . . . . . . . $10 \mathrm{ml}$

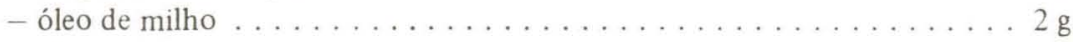

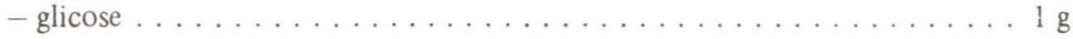

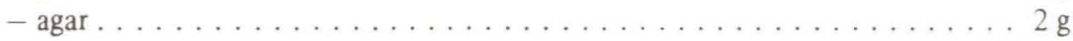

- agaroses ............................. $100 \mathrm{mg}$

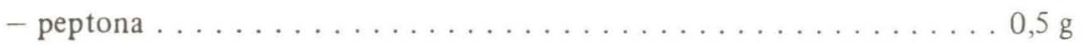

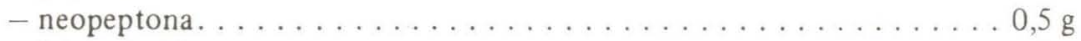

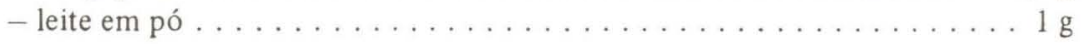

O material obtido das 2 primeiras coletas foi colocado, primeiramente no substrato $\mathrm{A}$, passando ao $\mathrm{B}$ no estágio de larva 2. Os ovos da terceira coleta foram colocados diretamente sobre o substrato $\mathrm{B}$ objetivando a tentativa de aumento do número de eclosões.

Foi usado "Pumpel's fluid" (DUFFY, 1960) como conservante de ovos, larvas e pupas. Estas foram separadas diariamente, uma à uma e colocadas em pequenos frascos.

Os adultos obtidos e suas peças foram fixados em álcool $70 \%$.

Os desenhos foram feitos sob microscópio estereoscópico e as fotos através do microscópio eletrônico de varredura. Para tanto, o material foi retirado diretamente do álcool para os stubbs, sem qualquer preparo prévio.

Os dados da biologia apresentam-se organizados em tabelas.

O material estudado encontra-se depositado na coleção de referência do CIFURB.

\section{RESULTADDOS E DISCUSSÕES}

\section{OVO}

Com casca de aparência lisa sob microscópio ótico, e ao microscópio eletrônico, com $40 \mathrm{x}$, com textura rugosa (Fig. 1). 
Existem discrepâncias na literatura sobre os períodos de ovulação e eclosão, sem registros se estes incluem o tempo em que são contidos no neossoma. BONNET (1887) registra que a ovulação dura 8 à 9 dias, podendo chegar ao $15^{\circ}$. dia; também relaciona a postura ao contato com o ar livre e não com o tecido cutâneo. FAUST \& MAXWELL (1930) afirmam que em uma semana os ovos estão maduros e SEGUY (1951) que a eclosão se dá 10 dias após a postura. BRUCE et al. (1942) e DEL PONTE (1958) dizem que as larvas aparecem em 3 a 4 dias. Para COUTINHO (1957) os ovos dão larvas em 8 dias.

A constatação presente está expressa no quadro abaixo:

$\begin{array}{cclc}\text { Data da postura } & \text { No de ovos } & \text { Eclosão } & \text { N. de larvas } \\ -02 / \mathrm{VI} & 2.349 & 06 / \mathrm{VI} & 465 \\ -06 / \mathrm{VI} & 1.453 & 08-13 / \mathrm{VI} & 129 \\ -08 / \mathrm{VI} & 767 & 10-13 / \mathrm{VI} & 5\end{array}$

Foi observado que a postura parece estar relacionada à temperatura, pois, no homem, a velocidade de eliminação dos ovos é maior e aumentou consideravelmente, quando o calor foi aplicado diretamente ao parasita. O aumento de temperatura foi obtido através de dois métodos: colocação da fêmea recém-extraída em pedaços de carne crua aquecida e, imersão do pé do parasitado em água a aproximadamente $52^{\circ} \mathrm{C}$. Em fêmeas recém extraidas, a eliminação dos ovos, continuou lenta, um a um irregularmente.

\section{LARVA}

HICKS (1930) registra que as antenas encontram-se apoiadas em área elevada, limitada por engrossamento da cutícula a qual está cercada por 3 papilas grandes e 3 pequenas; BONNET (op. cit.) falta de uma "eminência mamelonada situada sobre escavação de uma peça córnea". Foi observado que esta área é retrátil, expandindo-se de acordo com os movimentos da larva, para dentro e para fora, no sentido do comprimento. As papilas coniformes encontradas em todos os exemplares observados foram: 3 grandes e 2 pequenas, sempre na superfície da peça córnea e portanto, às vezes, mais aparentes (Fig. 2 e 3).

As antenas são constituídas de um segmento cuminado por uma cerda e apoiadas na base córnea retrátil. Não se tratam de 2 segmentos, uma vez que não existem articulações (Fig. 2).

As mandibulas são triangulares e apresentam-se, conforme HICKS (op. cit.) contrariando BONNET (op. cit.), com 3 dentes cegos de tamanhos decrescentes. Todavia, seguem-se 2 fileiras paralelas de 4 dentes na face superior e 5 dentes na inferior (Fig. 4), o que discorda de ambos os autores que registram 3 e 6 dentes e " 5 a 6 cerdas duras", respectivamente.

Os apêndices anais, descritos por BONNET como terminados por " 3 eminências mamelonadas... as últimas são os pés da larva..." e por HICKS como apresentando "2 lóbulos, cada um $\infty \mathrm{m}$ um apêndice anal quitinoso com a forma de um triângulo isóscele", têm, na realidade, outra configuração. Foi possivel registrar a existên cia de duas saliências mamelonadas, com um apêndice anal quitinoso desta mesma forma no ápice de cada uma e, mais duas projeçôes, perfeitamente visíveis, em vista ventral, que funcionam como pés (Fig. 5). 
Revta bras. Zool.
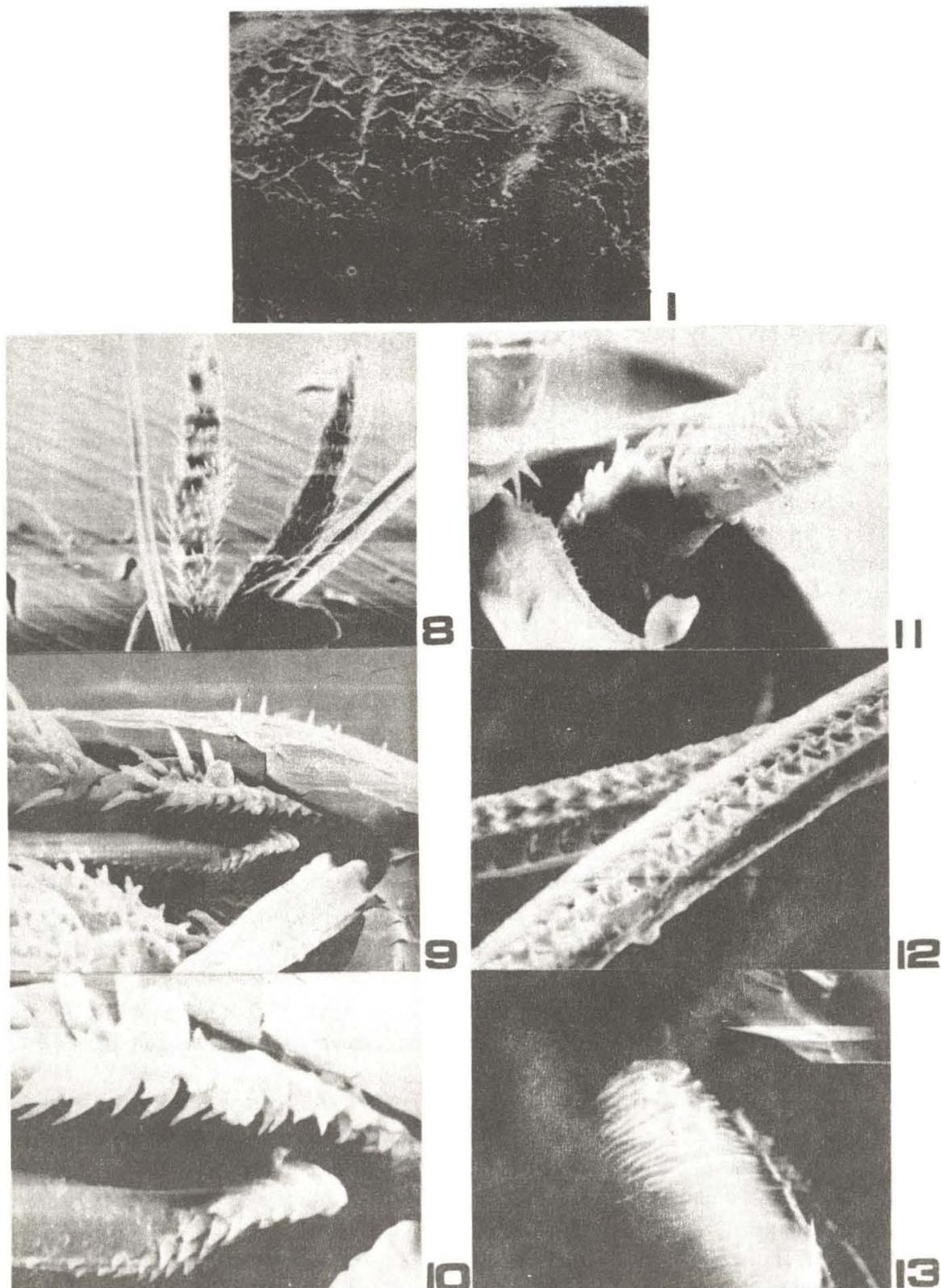

Pig. 1 - Ovos - superfície da casca. Figs. 8-13: adulto: cabeça. Vista ventral. 8. Palpo maxilar; vista frontal; 9-10. Cerdas e dentes da base da maxila; 11. Face lateral; 12. Mandibula com dentes; vista lateral; 13. Artículo apical da antena. Escalas. 40X, figs. 1, 8; 10X, figs. 9, 11, 12, $13 ; 4 \mathrm{X}$, fig. 10. 
Vol. 7(1-2), 1990

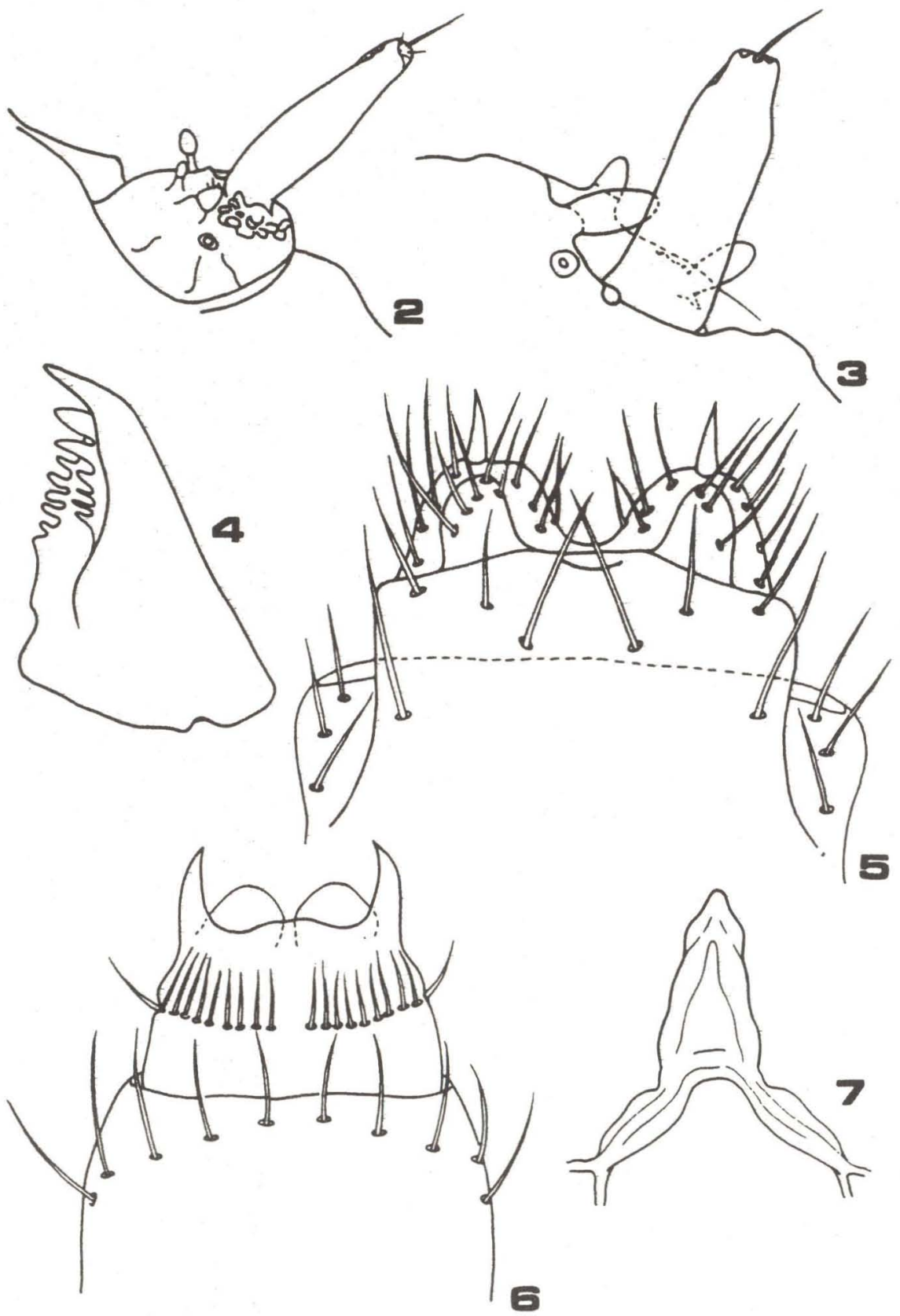

Fig. 2-7 - Larva: Antena. Vista lateral. 2. Peça córnea expandida; 3. Peça córnea retraída; Mandibula. 4. Vista lateral; Abdomen. Vista ventral. 5. Segmentos finais com saliências mamelonadas, apêndices anais e projeções; Vista dorsal. 6. Segmentos finais com distribuição de pêlos; EGG-BREAKER. 7. Vista dorsal. Escalas: 400X. Figs. 2, 5, 6; 1000X Figs. 3, 4, 7. 
HICKS registra 12 pêlos, de tamanhos iguais, no 9 ? segmento abdominal e aproximadamente 75 pêlos, de tamanhos diversos, no segmento final. Observa-se, todavia, que no 9 ? segmento existe uma fileira de 10 pêlos regulares; no segmento final há uma nítida fileira de 20 pêlos, visíveis em vista dorsal (Fig. 6) e inúmeros pêlos irregulares, em disposição e tamanho, na face ventral. Estes últimos são caducos. Isto torna impossível estimar o seu número exato.

Existem discrepâncias quanto à duração do período larval obtida pelos diferentes autores BONNET refere-se ao periodo larval como sendo de 08 a 10 dias, no máximo. BRUCE et al. (op. cit.) afirmam que a pupa apare ce "após sucessivas mudas" e o adulto 28 dias após a postura; COUTINHO (op. cit.) que em 3 semanas a larva atinge o estado adulto; JAMES (1969) que, sob condições favoráveis, em 10 a 14 dias cumpriu-se o período larval e REY (1973), que "após uma" ecdise a fase adulta chega em "17 dias ou mais".

Constatou-se que o período larval inicia-se no 3 ? dia após a postura, desenvolvendo-se até o $13^{\circ}$ dia podendo chegar ao $18^{\circ}$. abrangendo estágios de L1 e L2.

HICKS refere-se ao "egg-breaker" (ruptor ovi) como sendo uma estrutura triangular, de ápice agudo, cuja forma é diagnóstica para Tunga. Sob o microscópio estereoscópio identificam-se 2 partes: a superior, laminar, subtriangular, e a inferior, alongada, com quilha proeminente, de ápice triangular voltado para cima. A primeira parte sobrepõe-se à segunda e ambas se acham inseridas na porção mediana dorsal da linha de sutura, entre a cabeça e o 1 ? segmento torácico (Fig. 7).

\section{PUPA}

BONNET registra o $3^{\circ}$. dia do desenvolvimento da pupa como o do aparecimento da crisálida e com dimensões de $0,65 \mathrm{~mm}-0,30 \mathrm{~mm} ; 3$ dias depois já está adulto, solto no interior do casulo e pronto para eclodir; as transformações ocorrem em menos de 8 dias, podendo variar de acordo com as "vicissitudes atmosféricas".

Neste trabalho, constatou-se que, já no 2 ? dia, desapare ce o delineamento da larva surgindo, em seguida, a pupa que mostra o tegumento da cabeça e da terminália coladas à sua face ventral; o tamanho é de $1,53 \mathrm{~mm}-1,42 \mathrm{~mm}$; no $8^{\circ}$. dia observa-se o corpo perfeitamente delineado e somente no $10^{\circ}$ dia chega a adulto. A investigação sobre alguns casulos mantidos em placas com substrato A, onde não eclodiram adultos, mostrou que neles haviam ácaros que, possivelmente, tornaram as pupas plasmolisadas.

Convém salientar que para BONNET, mesmo surgindo a crisálida no $3^{\circ}$. dia, só apareceu o adulto no 8 ? dia. Todavia, verificou-se que as larvas que chegaram à crisálida no 2 ? dia, transformaram-se em adultos perfeitos até o $10^{\circ}$. dia.

\section{ADULTO}

VAZ \& URIEL (1946) observam que o artículo I dos palpos maxilares é o maior; comprovou-se que isto refere-se ao artículo II( Fig. 8). JOHNSON (1957) registra que o artículo basal dos palpos maxilares possui cerdas largas, grosseiras, numerosas, espiniformes e algumas excedendo o diâmetro do palpo; diz ainda, que à base da maxila, anteriormente, situam-se 3 crdas relativamente grandes e grosseiras. Os artículos são realmente cobertos por cerdas, mas nunca mais longas que o diâmetro do palpo, em nenhum deles (Fig. 8), à base da maxila foi possível visualizar 5 cerdas grandes e grosseiras (Fig. 9) ao mesmo tempo que observou-se ser o bordo interno do artículo basal, na inserção 
Vol. 7(1-2), 1990

da epifaringe, coberto por finas cerdas esquamiformes (Fig. 10). Cumpre ressaltar que a face interna do artículo basal do palpo maxilar é completamente isenta de pêlos e algo rugosa (Fig. 11). As cerdas dos artículos do palpo maxilar têm disposição linear e alternada e as bordas laterais são maiores do que as da superfície. A mandibula apresenta-se denteada na face externa e perfurada na interna (Fig. 12); o artículo apical da antena possui superfície rugosa, com cerdas apicais e 3 laterais (Fig. 13).

\section{CONCLUSÕES}

Face a novas observações feitas, pode-se afirmar que os estágios de desenvolvimento de Tunga penetrans caracterizam-se por apresentar:

OVOS: * superfície rugosa a nivel de microscopia eletrônica.

LARVA: * mandibula com três dentes cegos de tamanhos decrescentes e duas fileiras paralelas de quatro dentes na face superior e cinco dentes na inferior.

* estrutura anal e quetotaxia particulares: no 9 ? segmento existe uma fileira de 10 pêlos regulares; no segmento final há uma nítida fileira de vinte pêlos, visíveis em vista dorsal (Fig. 6) e inúmeros pêlos irregulares em disposiçâo e tamanho, na face ventral. Estes últimos são caducos. Isto torna impossível estimar seu número exato.

* egg-breaker (ruptor ovi) com duas partes diferenciadas: a superior, lânar, subtriangular, e a inferior, alongada, com quilha proeminente, de ápice triangular voltado para cima. A primeira parte sobrepõe-se à segunda e ambas acham-se inseridas na porção mediana dorsal da linha de sutura, entre a cabeça e o primeiro segmento torácico (Fig. 7).

ADULTO: * palpos maxilares apresentando artículo basal com cerdas nunca maiores do que o diâmetro do palpo; base da maxila anterior com cinco cerdas grandes e grosseiras e seu bordo interno e base da epifaringe coberto por finas cerdas esquamiformes; cerdas superficiais de disposição linear alternada; as duas bordas laterais maiores do que as superficiais; face interna, em um artículo, sem pêlos e rugosa.

* dimensões dos artículos destes palpos dispostos em ordem decrescente de tamanho, como segue: II, IV, I e III;

* mandibula com as diferentes faces portadoras de escultura diversa: denteada na face externa e perfurada na interna;

* revestimento do artículo apical da antena caracteristico, com superfi. cie rugosa e apresentando três cerdas laterais e cinco no ápice.

DIETA: * o substrato B utilizado para o desenvolvimento larval, tave como vantagem a inexistência de predadores.

\section{AGRADECIMENTOS}

Ao Dr. Francisco Kiss do Departamento de Paleontologia e Estratigrafia do Instituto de Geociências da Universidade Federal do Rio Grande do Sul, pelas fotos em microscopia eletrônica de varredura.

Ao Dr. Pedro Marcos Linardi do Departamento de Parasitologia da Universidade Federal de Minas Gerais pela consultoria. 


\section{REFERÊNCIAS BIBLIOGRÁFICAS}

BONNET, P.G. 1887. Memoire Sur La Puce Penetrante ou Chique ARCH. DE MED. NAV. 8 (6): $81-118$

BRASIL. 1966. Ministério da Marinha. BRASIL - RIO GUAİBA DE ITAPUĀ À PORTO ALEGRE. Escala 1:50000/s.l.p.

BRUCE, M.C.O. et ali. 1942. A discussion of the Chigoe (Tunga penetrans) based on experiences, in British Guiana. THE MILITARY SURGERON. 91: 446-52.

COUTINHO, E. 1957. Tungidae. TRATADO DE CLINICA DAS DOENÇAS INFECCIOSAS, PARASITÁRIAS E PEÇONHENTAS. Ed. Guanabara Koogan, RJ.

DEL PONTE, E. 1958. MANUAL DE ENTOMOLOGIA MÉDICA Y VETERINÁRIA ARGENTINAS. Buenos Ayres, Libreria del Colegio.

DUFFY, E.A.J. 1960. A monografh of the immature stages of neotropical timber beet les (Cerambycidae), $/ 7 /+327$ pp., 13 pls., 176 figs., front. British Museum (Natural History), London.

FAUST, E.C. \& MAXWEEL, T.A. 1930. The finding of the larvae of the Chigo, Tunga pen etrans, in scrapings from human skin. ARCHIVES OF DERMATOLOGY AND SYPHILOLOGY. Ame rican Medical Association. Chicago, 22:94-97.

HICKS, E.P. 1930. The early stages of the jigger, Tunga penetrans. AN. TROP. MED. PARASIT. $24: 575-86$.

JAMES, M.T. et ali. 1969. MEDICAL ENTOMOLOGY. 6. ed. Londres, Macmilland Company. 306, 317-19.

JOHNSON, P.T. 1957. Fleas of South America. MEMOIRS OF THE EN TOMOLOGICAL SOCIETY. S: $233-258$.

REY, L. 1973. PARASITOL OGIA. Editora Guanabara Koogan.

SÊGUY, E. 1951. Ordre des Siphonapteres. In: GRASSE-PIERRE, P. TRAITÉ DE ZOOLOGIE (Ana tomie, sistemátique, biologie). Paris Masson et Cie Éditerus T. 10, fasc. 1, p. 745-61; $765-66$.

SINGH \& PRITAN. 1976. ARTIFICIAL DIETS F OR INSECTS, MITES AND SPIDERS. IFI/Plencs. NY/Washington/London.

VAZ, Z. \& URIEL, F.R. 1946. Tunga penetrans, "Bicho-do-pé" em gado bovino. Livro de Homenagem à R. F. D'Almeida. No 40:327-332. 